We think that their suggestion that general practitioners should treat empirically for Chlamydia trachomatis infection is highly inflammatory. A they admit, this infection has an appreciable morbidity; the correct management of such sexually transmitted infections requires accurate diagnosis, effective treatment, adequate tests of cure, and, very importantly, examination and treatment if necessary of all sexual partners. Suboptimal management, as they suggest, has no doubt contributed to the rising incidence of $C$ trachomatis infection over the past decade.

We stand by our recommendations that screening for genital infections be performed in selected women who have had one smear showing in flammatory changes and in women undergoing colposcopic examination because of repeated smears showing inflammatory changes. Such policies should encourage closer links between departments of genitourinary medicine and colposcopy clinics, which can only be of mutual benefit to patients and staff.

J D WILSON A J ROBINSON

Royal Hallamshire Hospital, Sheffeld S10 2JF

SIR, - The recommendation that young single women with inflammatory changes on cervical cytology should be screened for sexually transmitted diseases, made by Dr Janet D Wilson and colleagues, is useful and relevant.' To what exten such women should have a colposcopic examination is less clear. It would seem appropriate to perform repeat cytology in such women after their infection(s) have been treated. Indeed, the authors repeated the smear tests immediately before colposcopy-the results of these tests are not, however, given.

Several reports have suggested that persistent findings of inflammatory changes and other minor abnormalities in cervical smears may mask an underlying cervical intraepithelial neoplasia lesion. ${ }^{2+} \mathrm{Dr}$ Wilson and colleagues performed colposcopy in women with a single smear showing inflammatory changes. In all, 36 out of 96 women examined had abnormalities on colposcopy. In most of these (27) there was evidence only of wart virus infection or cervical intraepithelial neoplasia type I. (These diagnoses were presumably supported by histological results.) Women with an abnormality on colposcopy were more likely to be younger than those without such an abnormality.

I have recently completed a survey of findings on colposcopy in a series of 130 predominantly young women. I was surprised that about a third of them had abnormalities, most of which when biopsied showed evidence of wart virus infection or cervical intraepithelial neoplasia type I (M Griffiths, unpublished work). Giles $e t$ al have shown that colposcopy is more sensitive than cytology at detecting cervical epithelial abnormalities but that the excess of abnormalities is mostly due to small low grade lesions, which may not be of clinical importance. I have reviewed some of the data from the paper of Giles et al and it would seem that within their study about a third of normal healthy women under 35 years had an abnormality on colposcopy. This calculation has been confirmed by one of the authors (P G Walker, personal communication). In a controlled study in immunosuppressed women abnormalities were found on colposcopy in $29 \%$ of controls.

It seems that the prevalence of abnormalities found by Dr Wilson and colleagues on colposcopy was no greater than would have been expected in a group of young women from the general population. Therefore, although their advice regarding screening for sexually transmitted diseases is valid, the decision to refer for colposcopic assessment should continue to be based on either persistent findings of mild abnormality or definite evidence of dyskaryosis on repeat smear testing.

MALCOLM GRIFFITHS

Buckinghamshire HP10 9AW

1 Wilson JD, Robinson AJ, Kinghorn SA, Hicks DA. Implications of inflammatory changes on cervical cytology. $\mathrm{Br}$ Med 1990;300:638-40. (10 March $)$

2 Soutter WP, Wisdom S, Brough AK, Monaghan JM. Should patients with mild aty pia in a smear be referred for colposcopy? Br f Obstet Gynaecol 1986;93:70-4.

3 'Tay SK, Jenkins D, Singer A. Management of squamous atypia borderline abnormalities): repeat cytology or colposcopy? Aust NZ F Obstet Gynaecol 1987;27:140-1.

4 Walker PG, Singer A. Colposcopy: who, when, where, and by whom? Br f Obstet Gynaecol 1987:94:1011-3.

5 Giles JA, Hudson E, Crow J, et al. Colposcopic assessment of the accuracy of cervical cytology screening. Br Med $\mathcal{F}$ 1988;296: accuracy

6 Alloub MI, Barr BB, McLaren KM, et al. Human papillomavirus infection and cervical intraepithelial neoplasia in women with renal allografts. Br.Med $\mathcal{F}$ 1989;298: 153-6.

\section{Should fertile people have access to in vitro fertilisation?}

SIR,-We agree with Dr Marcia Ratcliffe and colleagues that efforts should be intensified to circumvent infertility induced by treatment, but their suggestions that women with lymphoma should have access to assisted reproduction techniques before cytotoxic chemotherapy' do no support extension of in vitro fertilisation to the fertile. ${ }^{2}$ Many patients with cancer have impaired fertility even before cytotoxic chemotherapy, and the pretreatment storage of germ cells would thus have only a limited potential.

The use of superovulants - that is, fertility drugs - to allow embryo freezing may carry a cancer risk in women. ${ }^{+}$Excessive ovarian stimulation with fertility drugs during a single stimulated cycle may result in up to a fivefold increase in plasma oestrogen concentration, ${ }^{4}$ and excessive oestrogen secretion has been implicated in ovarian, endometrial, and breast cancer.

Gonadotrophin releasing hormone agonists such as goserelin down regulate pituitary gonadotrophin receptors, leading to a fall in circulating gonadotrophin concentration and a consequent reduction in ovarian production of oestrogen. These drugs thus oppose ovarian stimulatory drugs. Goserelin can induce remissions of advanced breast cancer in premenopausal women and in a smaller proportion of postmenopausal women, most likely through indirect ovarian suppression and a consequent reduction in plasma oestrogen concentration. My colleagues and I have shown that the ovaries of postmenopausal women retain residual hormonal function that partly depends on the integrity of the pituitary-ovarian axis

The gonadotrophin releasing hormone agonis leuprolide has induced remissions in patients with refractory ovarian cancer. These remissions could possibly have been induced in a similar manner to remissions in patients with breast cancer. This is supported by the finding of a positive relation between ovarian tumour volume and plasma oestradiol concentration ${ }^{8}$ and tumour expression of oestrogen receptors in about one third of patients with ovarian cancer. ${ }^{4}$ As gonadotrophin releasing hormone agonists that oppose fertility drugs can temporarily reverse progression of breast and ovarian cancer the fertility drugs might provoke or promote these cancers in some patients.

Recent promotion of in vitro fertilisation as a procedure applicable even to the fertile ${ }^{2}$ should be considered with caution. Fertility drugs before cytotoxic chemotherapy in patients with potentially curable lymphoma are unlikely to be effective and might increase the known risk of secondary malignancies. ${ }^{10}$ Other research strategies to preserve fertility in patients with curable cancers such as optimising the duration and content of combination cytotoxic chemotherapy and developing new anticancer drugs should also be explored.

University Department of Clinical Oncology

B CANTWELI.

Newcastle General Hospital.

Newcastle upon Tyne NE4 6B

Ratcliffe M, Fleet G, Dawson A, Templeton A. Should fertile people have access to in vitro fertilisation? $\mathrm{Br} . \mathrm{Mcd}$ 1990;300:607 (3 March

2 Dawson K, Singer P. Should fertile people have access to in vitro fertilisation? Br.Med 7 1990;300:167-70. (20 January.

3 Waxman J. Cancer, chemotherapy, and fertility. Br Med 1985;290:1096-7.

4 Fishel S, Jackson P. Follicular stimulation for high tech pregnancies: are we playing it safe? Br Med $\mathcal{F}$ 1989;299.

5 Henderson BE, Ross R, Bernstein L. Estrogens as a cause of human cancer: the Richard and Hilda Rosenthal Foundation award lecture. Cancer Res 1988;48:246-53.

6 Harris AL, Carmichael J, Cantwell BMJ, Dowsett M. Zoladex: endocrine and therapeutic effects in post-menopausal breast cancer. Br f Cancer 1989;59:97-9.

7 Kavanagh JJ, Roberts W, Townsend P, Hewitt S. Leuprolide acetate in the treatment of refractory or persistent epithelial ovarian cancer. F Clin Oncol 1989:7:115-8.

8 Mähilck C-G, Bäckström T, Kiellgren O. Plasma level of oestradiol in patients with ovarian malignant tumours. Gynecol Oncol 1988; 30:313-20.

9 Harding $M$, Cowan S, Hole D, et al. Estrogen and progesterone receptors in ovarian cancer. Cancer 1990;65:486-91.

10 Prosnitz LR, Farber LR, Kapp DS, et al. Combined modality therapy for advanced Hodgkin's disease: 15 year follow-up data. F Clin Oncol 1988;6:603-12.

\section{Treating renal anaemia with recombinant human erythropoietin}

SIR, - In their article Dr Iain C Macdougall and colleagues have rightly emphasised the cost of treatment with recombinant human erythropoietin and the constraint that this imposes on patient selection for treatment of the anaemia of chronic renal failure.' They suggest that patients awaiting transplantation of a kidney from a live related donor should not be among the lucky few receiving this treatment and, by inference, should receive blood transfusions for symptomatic anaemia. We argue that these patients' condition, and indeed that of potential transplant recipients in general, constitutes one of the more compelling indications for erythropoietin.

About $30 \%$ of patients awaiting renal transplantation are regarded as "highly sensitised"that is, they possess alloantibodies that react with more than $90 \%$ of a panel of cells that are representative of the donor population-and thus effectively are not able to receive a transplant; blood transfusions, previous transplantation, and pregnancy are the three principal causes of sensitisation. The alloantibodies may disappear in the long term in the absence of further transfusion, perhaps through the generation of anti-idiotypic networks, and, in rare cases, they can be removed by immunoadsorption. It is obviously preferable, however, not to provoke their generation in the first place. From the early 1970 s to the early 1980 s many centres reported the beneficial effect of blood transfusion before transplantation on graft survival. In recent years, for reasons that are not entirely clear, this beneficial effect no longer seems to operate (except perhaps for HLA matched and donor specific transfusions) and thus the one argument favouring transfusion over erythropoietin has collapsed.

Unless or until adequate funding is provided for the optimal use of erythropoietin renal physicians will be forced to select patients for this treatment. It is prudent for recipients of transplants from live related donors, who will require erythropoietin only in the short term, to be given preference. Sensitising a potential recipient of a live donor transplant by unnecessary blood transfusions not only is disastrous for the patient but means one 
more patient undergoing dialysis and on the waiting list for a cadaver organ.

Royal Postgraduate Medical School

Hammersmith Hospital,

London W'12 0NN

1 Macdougall IC, Hutton RD, Cavill I, Coles GA, Williams JD. Treating renal anaemia with recombinant human erythropoietin: practical guidelines and a clinical algorithm. Br.Med 7 1990;300:655-9. (10 March.)

2 Opelz G. Improved graft survival in nontransfused recipient. Transplant Proc 1987;19:149-52.

\section{Absorption of irrigating solution during transcervical resection of endometrium}

SIR, - Two of the comments made concerning our study of fluid dynamics during endometrial resection' show the false logic of applying the urological principles of transurethral prostate resection to the uterus. These misapprehensions are serious as their unconsidered application would lead to potentially unsafe and ineffective surgery at a time when this form of intervention is fast gaining popularity among gynaecologists and public alike.

Firstly, the question of uterine distension. The correct intrauterine pressure is the minimum pressure that produces adequate distension of the uterine cavity to allow for the identification of landmarks and a clear view during surgery. An irrigation pressure of $60 \mathrm{~cm} \mathrm{H}_{2} \mathrm{O}$ as recommended by Dr T C A Boto and colleagues ${ }^{2}$ may be sufficient to distend the compliant and thin walled bladder during endoscopic prostate resection ${ }^{3}$ but is wholly inadequate in the case of the non-compliant and thick walled uterus. As long ago as 1972 Quinones et al showed that although images of the uterine cavity are possible with a pressure of $40 \mathrm{~mm} \mathrm{Hg}$ $\left(54 \mathrm{~cm} \mathrm{H}_{2} \mathrm{O}\right)$, the pressure must be increased to $100-110 \mathrm{~mm} \mathrm{Hg}\left(136-150 \mathrm{~cm} \mathrm{H}_{2} \mathrm{O}\right)$ to identify the tubal orifices. ${ }^{+5}$ Our experience with intrauterine pressure measurements are broadly similar, some variability being afforded by factors such as uterine size and fibroids. It is of course essential to ensure proper uterine distension during hysteroscopic surgery to reduce the risks of perforation and other accidents as a result of poor visualisation.

The second comment refers to the questions of absorption of irrigant fluid overload, and disturbances in electrolyte concentrations. Analysis of the first 139 procedures showed that the median volume of $1.5 \%$ glycine solution absorbed during endometrial resection was $350 \mathrm{ml}$, with 35 of the patients absorbing more than $500 \mathrm{ml}$ and 11 more than 1 litre. The haemodynamic and biochemical consequences of fluid loads of up to 2 litres were well tolerated by these patients. This was probably a result of the rapid distribution of glycine solution throughout the 15 litres of extracellular water owing to the good cardiac and renal function of our relatively young female subjects, factors that are in contrast with those in most elderly men undergoing prostatic surgery. There is thus no reason to stop surgery once $500 \mathrm{ml}$ of uterine irrigant has been absorbed, as recommended by $\mathrm{Dr}$ Boto and colleagues, and leave the patient with the difficult choice between incomplete treatment or readmission and retreatment. Although relevant in only about $8 \%$ of cases, a more realistic approach in otherwise fit patients is to try to complete the procedure as quickly as possible once 1 litre of uterine irrigant has been absorbed and to stop, whatever the stage of surgery, when the fluid deficit is approaching 2 litres, at the same time checking serum electrolyte concentrations and assessing the clinical state of the patient. Such a protocol is not inconsistent with published urological practice ${ }^{t}$ and is certainly more conservative than the management of fluid dynamics during laser ablation of the endometrium.

Other points raised ${ }^{2}$ include the role of tubal loss of uterine irrigant and the use of $1.5 \%$ glycine solution to distend the uterus. Briefly, as reported recently, we have found that prior tubal blockage reduces the amount of uterine irrigant absorbed by the patient by an average of $20 \%(315 \mathrm{ml} v 400 \mathrm{ml})$, an identical value to that quoted by Quinones et al for diagnostic hysteroscopy. ${ }^{5}$ As for the choice of uterine irrigant, which we did not claim is isotonic, the use of $1.5 \%$ glycine solution in urology is traditional and based on the principle of the least amount of a non-electrolyte substance that could be added to distilled water to form a solution that would prevent haemolysis. ${ }^{10}$ Though $1.5 \%$ glycine solution is not the ideal irrigant, it has at least the benefits of experience. We agree, however, that the theoretical advantages of isotonic solutions should be investigated.

ADAM L MAGOS GILLIAN M LOCKWOOD RALF BAUMANN SIR ALEXANDER C TURNBULL JONATHAN D S KAY

University of Oxford,

John Radcliffe Hospital

Oxford OX3 9DU

1 Baumann R, Magos AL, Kay JDS, Turnbull AC. Absorption of glycine irrigating solution during transcervical resection of glycine irrigating solution during transcervical resection

2 Correspondence. Absorption of irrigating fluid during transcervical resection of endometrium. Br Med f 1990;300:748-9. (17 March.)

3 Mitchell JP. The principles of transurethral resection and haemostasis. Bristol: Wright, 1972:139.

4 Quinones RG, Alvarado DA, Aznar RR. Tubal catheterisation applications of a new technique. Am $\mathcal{F}$ Obstet Gynecol 1972;114:674-8

5 Quinones RG. Hysteroscopy with a new fluid technique. In Siegler AM, Lindemann HJ, eds. Hysteroscopy. Principles and practice. Philadelphia: Lippincott, 1984:41-2.

6 Dodson ME. Lithotripsy for renal stone disease. $\mathrm{Br} \mathrm{Med} \mathcal{f}$ 1985;291:1577.

7 Norlen H, Allgen L, Wicksell B. Sorbitol concentrations in plasma in connection with transurethral resection of prostate using sorbitol solution as an irrigating fluid. Scand $\mathcal{f} U$ rol Nephrol 1986;20:9-17

8 Morrison LMM, Davis J. Sumner D. Absorption of irrigating fluid during laser photocoagulation of the endometrium in the treatment of menorrhagia. Br 7 Obstet Gynaecol 1989;96: $346-52$.

9 Magos AL, Baumann R, Turnbull AC. Safety of transcervical endometrial resection. Lancet 1990;335:44

10 Nesbit RM, Glickman SI. Use of glycine as irrigating medium during transurethral resection. F Urol 1948;59:1212-7.

\section{Should pathologists talk to patients?}

SIR, - The report by Drs Stephen R Vallely and J O Manton Mills' and subsequent correspondence raise important issues regarding when patients should be told the results of tests and by which doctor - that is, by the referring clinician or by the clinician who carried out the test. It may come as a surprise that some pathologists are faced with the same dilemma.

Those institutes that are most experienced in fine needle aspiration cytology recommend that the aspirate should be taken by the doctor who also interprets the slides; this is usually the cytopathologist. 'Like some other pathologists in this country, ${ }^{4}$ we follow this recommendation and have for the past year offered a fine needle aspiration service on this basis. We normally ask patients to wait while the slides are stained and examined, and if we reach a confident benign diagnosis we inform the patient. As many of the patients are women with breast lumps this policy eliminates the usually highly anxious wait of up to a week.

Most of our patients are seen in an outpatient setting where the surgeon and nursing staff are available for support, and in these cases patient with malignant disease are also told of the diagnosis unless there is a reason not to. Occasionally we diagnose malignancy in the absence of the referring clinician, and this provides us with a problem. In our experience once the patient knows that we have examined the slides she expects to be told the results and few are worried whether the doctor who tells them is a surgeon or a cytopathologist, provided that they get a rapid and honest answer delivered with tact, and we endeavour to give this. We believe, however, that these patients should see the appropriate referring surgeon as quickly as possible in order to discuss different treatment possibilities.

P C H WATT

L CAUGHLEY

$M$ VARMA

Department of Cytopathology,

Royal Victoria Hospital

Belfast BT12 6BA

I Vallely SR, Mills JOM. Should radiologists talk to patients? Br Med f 1990;300:306-6. (3 February.)

Correspondence. Should radiologists talk to patients? $\mathrm{Br}$ Med $f$ 1990;300:610. (3 March.)

3 Hajdu SI, ed. The value and limitations of aspiration cytology in the diagnosis of primary tumours. A symposium. Acta Cytol 1989:33:741-96.

4 Zuk JA, Maudsley G, Zakhour HD. Rapid reporting of fine needle aspiration of breast lumps in outpatients. $\mathcal{F}$ Clin Pathol 1989;42:906-11.

\section{Private patients preferring to use NHS facilities}

SIR,-We must thank Dr A C Fairbank and colleagues for reporting what most clinicians have suspected for a long time: that a substantial number of patients using NHS facilities have insurance that would enable them to use the private sector without personal cost. ${ }^{\prime}$ They do this because they are happy with the care in NHS hospitals, especially in specialties such as day surgery, in which the private sector lags far behind. Even if private facilities are available these patients will not choose to use them.

Surely, therefore, what is needed is a way to induce such people to become paying patients in NHS hospitals rather than to steer them towards the private hospitals which would be their second choice. Many would willingly become paying patients for very little in return, having most of what they want already at basic NHS level. A patient of mine illustrated this well when she commented to the unit manager who visited the operating theatre where she was undergoing caesarean section under epidural anaesthesia that it couldn't have been better if she had used her BUPA card. Asked why she hadn't done, she replied that she did not know that the option was there.

A way is needed to encourage such patients without making non-paying NHS patients feel second class. The benefit to district hospitals if $10 \%$ of their patients were paying would be considerable.

Hinchingbrooke Hospital

M J HARE

Cambridgeshire PE18 8NT

I Fairbank AC, Stapleton SR, Jarrett PEM. Patients with private health insurance using NHS facilities in preference to private care. Br.Med f 1990;300:719. (17 March.)

\section{Correction}

\section{Anaesthetic awareness}

An editorial error occurred in this letter by Drs J N Lunn and M Rosen (7 April, p 938). The recommendation is that the end tidal concentration of the volatile agent should be maintained at 0.6 minimal alveolar concentration and not $0.6 \%$ as published. 